\title{
El tomismo analítico en Cracovia y en otros lugares*
}

The analytical thomism in Krakow and elsewhere

Recibido: 18 de diciembre de 2013 - Revisado: 14 de mayo de 2014 - Aceptado: 06 de noviembre de 2014

Roger Pouivet

En un pequeño libro, publicado en 1997, Après Wittgenstein, saint Thomas $^{* *}$ (Pouivet, 1997a), he presentado lo que se llama el tomismo analítico $^{* * *}$ en el dominio de la filosofía de la mente. Aquí, el acento será colocado sobre otro aspecto del tomismo analítico, más esperado tal vez, su lugar en la filosofía de la religión.

No se trata de la filosofía medieval. Conviene más bien hablar de una modesta contribución a la historia de la filosofía del siglo XX. El tomismo analítico ha tomado dos formas. La primera le fue dada por los filósofos polacos del Círculo de Cracovia en los años treinta. La segunda se comenzó en Gran Bretaña en los años cincuenta, con Elizabeth Anscombe, Peter Geach o Anthony Kenny. Se desarrolla hoy principalmente dentro de la filosofía de lengua inglesa. A pesar de su carácter contemporáneo, el tomismo analítico ha preservado el espíritu de los problemas filosóficos planteados por el Aquinate, sin por lo tanto ligarse a lo escrito.

\section{Neotomismo y filosofía analítica}

El neotomismo se ha desarrollado en la línea de la encíclica de León XIII Æternis Patris (1879). Esta encíclica prolonga el proceso iniciado en el siglo XVIII y en la primera mitad del siglo XIX por los jesuitas y los dominicos italianos. Probablemente se buscaba demarcar el pensamiento de santo Tomás de las tentativas sincréticas, como aquella de Rosmini, mezclando tomismo y kantismo. En sus diversas formas, el neotomismo se alimenta de feroces debates sobre puntos de interpretación doctrinal de santo Tomás. En particular, se interrogaba sobre la cuestión de saber si santo Tomás propone una

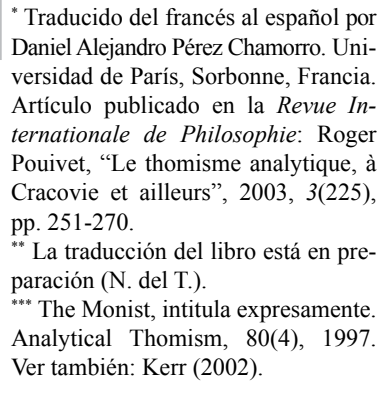

" Traducido del francés al español por Daniel Alejandro Pérez Chamorro. Universidad de París, Sorbonne, Francia. Artículo publicado en la Revue Internationale de Philosophie: Roger Pouivet, "Le thomisme analytique, à Cracovie et ailleurs", 2003, 3(225), pp. 251-270.

${ }_{* * *}^{*}$ La traducción del libro está en preparación (N. del T.).

${ }_{* * * *}$ The Monist, intitula expresamente. Analytical Thomism, 80(4), 1997. Ver también: Kerr (2002). 
filosofía y si es así, ¿cuál? ${ }^{1}$ Pensamos en las obras de Jacques Maréchal, Jacques Maritain, Étienne Gilson o Jacques Mandonnet. Al menos puntualmente, el debate se concentra sobre la respuesta que se debe dar a la máquina de guerra laica Émile Bréhier “¿Hay una filosofía cristiana?"2, dirigido contra la noción de "filosofía cristiana"3.

En el origen, el neotomismo correspondía a la voluntad de dar a los cristianos una filosofía que podría contrabalancear racionalmente las consecuencias antiteístas de los filósofos de la Ilustración (Voltaire, D'Alembert, Rousseau) proponiendo un pensamiento de concurrencia de los otros sistemas filosóficos de la tradición alemana (Fichte, Schelling, Hegel $)^{4}$. El neotomismo, a pesar de las divisiones internas, se ha opuesto globalmente a las corrientes "modernistas". Notemos que la tradición austríaca en filosofía, aquella de Bolzano y de Brentano, antikantiana, no se ha adherido a ese neotomismo. Probablemente, la filosofía austríaca estaba tan cerca intelectualmente de Aristóteles y de Tomás que no tenía necesidad de tender al "renacimiento", un defecto del cual no se escapaba siempre el neotomismo ${ }^{6}$. A veces el interés por santo Tomás hace pensar en esas fiestas campestres en las cuales se sacan los viejos arados y un par de bueyes para jugar a los paisanos de antaño. Eso se acompaña de una mitología de una Edad Media "edad de oro", eco invertido y también fantástico de la leyenda positivista de una Edad Media "edad de tinieblas". Nada de eso existía en Brentano de la misma manera que en el tomismo analítico.

Mutatis mutandis, Peter Geach, Elizabeth Anscombe, Anthony Kenny, Ralph McInerny, Norman Kretzmann, Brian Davies, David Braine, John Haldane y otros, son los principales filósofos a reagrupar en la denominación de "tomismo analítico" ". Eso no quiere decir que son simples exegetas de santo Tomás, incluso si algunos, Kretzmann o McInerny por ejemplo, son también excelentes exegetas. Algunos pueden incluso dada la ocasión rechazar una $\mathrm{u}$ otra tesis y pretender mejorarla. No hace falta decir que el tomismo analítico no es una ideología (la simple conceptualización de presuposiciones). Las problemáticas filosóficas desarrolladas por santo Tomás tienen su lugar dentro de la filosofía analítica, siempre y cuando se sepa introducirlas. John Haldane (1997) enuncia:

El tomismo analítico no busca apropiarse de santo Tomás para mejorar un conjunto particular de doctrinas. Tampoco se trata de un movimiento piadoso exegeta. Sin embargo, el tomismo analítico procura utilizar los métodos y las ideas de la filosofía del siglo veinte, al menos de la filosofía dominante dentro de los países de lengua inglesa, relativamente de la estructura general de las ideas introducidas y desarrolladas por Tomás (p. 486).

El parentesco metodológico y estilístico entre la filosofía escolástica y la filosofía analítica ha sido varias veces resaltado, de forma laudatoria e irónica. Se ha podido hablar de Tomás de Aquino y de Guillermo de Ockham como precursores de Frege (Michon, 1996) ${ }^{8}$. La similitud entre la teoría de referencia de Goodman y la lógica medieval de los términos, especialmente aquella de Ockham, es manifiesta (Panaccio, 1991; Pouviet, 1997b). Los acercamientos entre los problemas noéticos de los medievales y algunos aspectos de la filosofía analítica de la mente han sido numerosos $^{9}$. De una manera más general, se ha podido incluso decir que "los estudios sobre la lógica han participado de un modo notorio en la renovación de los estudios medievales estos últimos decenios" (Biard citado en Michon, 1996).

La historia propia de la filosofía analítica del siglo XX reconduce hacia los problemas y las posiciones filosóficas que ya han sido formulados por los medievales y singularmente por santo Tomás, al menos si se leen con las gafas analíticas ${ }^{10}$. 


\section{La reconstrucción analítica de Tomás de Aquino}

La práctica escolástica de los filósofos analíticos se convierte en una discusión argumentativa de los lugares comunes filosóficos. Se diferencia netamente de la tradición del comentario, propia de la filosofía alemana, heredada de una tradición hermenéutica. Esta última, como filosofía de los corpus, trata una obra filosófica como objeto de glosas y de interpretaciones y no como un objeto de análisis destinado a determinar si lo que sostiene es verdadero o falso. La filosofía analítica es directa y no histórica (u oblicua). Eso la opone claramente a la tradición "continental" alemana o, al menos por una parte, francesa.

Podremos afirmar que santo Tomás pertenece a la filosofía de los corpus, ya que ha comentadoAristóteles, Boecio, Pseudo Dionisio, el Libro de las causas, y por supuesto los textos bíblicos. Sus comentarios sobre Aristóteles se ligan al difícil problema de las conexiones entre teología y filosofía, entre fe y razón -se trata de mostrar la compatibilidad entre las dos, según lo que Paul Helm llama el programa de la fe en búsqueda de la inteligencia-. Esto se puede encontrar también, aunque de manera diferente, en Agustín, Anselmo y Tomás (Helm, 1997). Para este último, los comentarios de los textos sagrados forman parte de su función principal: legere, disputare, praedicare. Observamos por un lado que en sus comentarios Tomás emplea un método analítico, por reconstrucción y evaluación de los argumentos, y no la glosa, que llamaríamos hoy una hermenéutica, queriendo principalmente capturar un sentido latente ${ }^{11}$. Por otro, el comentario no consiste en parte de su trabajo filosófico y teológico. Sus dos sumas, la Suma teológica y la Suma contra los gentiles, cada una en su género propio, y las preguntas disputadas que él ha redactado, no son comentarios -su De ente et essentia tampoco- ${ }^{12}$. Incluso cuando discuten Aristóteles, Agustín, Dionisio u otros autores, esos textos tratan directamente los problemas que deben ser resueltos con el fin de alcanzar la verdad en los temas que se abordan, y no para hacerse un eco de una verdad que ya fue anunciada, y que debe glosarse e interpretarse. En santo Tomás, el recurso a las autoridades es un método de examen de las tesis, por una reconstrucción que los emplaza dentro de una argumentación original, independiente de la práctica del comentario. El tomismo analítico retoma esta tradición de un tratamiento directo de los temas, manifiesta dentro de la práctica de las cuestiones divididas en artículos.

El tomismo analítico participa en una concepción de la historia de la filosofía que se encuentra comúnmente dentro de la filosofía analítica, aquella de la reconstrucción teórica. Como dice Claude Panaccio, la idea de base es que "la exposición de una tesis o de un argumento filosófico venido de otra época no es nunca pura repetición" (Boss, 1994, p. 175) ${ }^{13}$. No se puede limpia y simplemente hacer presente en la conciencia el pasado, sino reconstruirlo.

Esta tesis de la reconstrucción histórica no es relativista. No contesta que podamos equivocarnos sobre el significado de lo que expresan los autores del pasado, que podamos deformar lo que dicen y traicionarlos. Puesto que heideggerianos y analíticos se relacionan de un modo diferente con Aristóteles, sin duda no pueden tener razón en cuanto a lo que Aristóteles pudo haber querido decir ${ }^{14}$. Comparten sin embargo la idea de que, comprender a un filósofo supone una forma de reconstrucción teórica y que lo que expuso Aristóteles supone una decisión sobre lo que quiso decir, sobre su intención filosófica.

Las razones que nos harán preferir, una reconstrucción u otra, hace caso omiso de las limitaciones de fidelidad. Dos reconstrucciones diferentes e incluso incompatibles deben respetar sus limitaciones de fidelidad, para ser tan solo reconstrucciones y no ficciones tomando por pretexto un autor o una época, como den- 
tro de una fábula borgesiana. Las limitaciones de reconstrucción son ante todo, limitaciones de corrección. Pero varias reconstrucciones correctas son posibles. Un enunciado de un idioma A puede ser correctamente traducido dentro de uno o varios enunciados de un idioma B, según las hipótesis de traducción que son hechas. De acuerdo con Quine, se puede decir que la indeterminación de la traducción no significa que no haya traducción aceptable, sino que hay a menudo varias ${ }^{15}$. Así mismo, las reconstrucciones diferentes, satisfaciendo el criterio de corrección, son posibles.

Las diversas reconstrucciones correctas tienen su pertinencia propia $^{16}$. Esta pertinencia es una lectura. Las traducciones igualmente correctas no son todas buenas. Pero el criterio gracias al cual se puede decir cuál es mejor, no tiene nada que ver con la corrección de la traducción. El criterio de pertinencia es pragmático y no semántico. ¿De qué le sirve esta traducción? ¿Por qué o incluso para quién la hacemos? ¿Dentro de qué contexto el texto traducido es leído? Una lectura filosófica posee también un contexto. Aparece como una respuesta a los problemas filosóficos que nos hacemos y pase lo que pase se inscribe dentro de los términos de esos problemas.

Según lo que se quiere explotar de una doctrina antigua para enriquecer los debates filosóficos actuales, para una mejor ubicación del punto de vista teórico, un momento particular dentro de la historia del pensamiento, e ilustrar una tesis general sobre la lógica del discurso filosófico o por cualquier otra razón, los criterios de adecuación (nosotros diríamos, de corrección) de la reconstrucción podrán variar considerablemente (Panaccio, 2000, p. 179).

Se discrimina un criterio de corrección de un criterio de pertinencia. Pero, mirando más de cerca, siempre es más difícil distinguirlos. Funcionan juntos. Dentro del criterio de corrección se opera sin duda el interés por la filosofía que leemos. La corrección no puede ser impasible a la reconstrucción misma, a la reactivación que provoca textos, que se utilizan para hacer otra cosa distinta a lo que el autor generalmente ha buscado, para responder a las preguntas que son parcialmente idénticas a las ciencias, así fuera porque el contexto es diferente. Sin duda, se puede reclamar que una reconstrucción se obligue a expresar las exigencias creíbles de corrección. Si están muy marcadas por el criterio de pertinencia, entonces el beneficio de la referencia a un autor del pasado desaparece. Mejor filosofar sin recurrir a lo que ya se ha escrito. El criterio de pertinencia debe entonces afinarse con suficiencia para que la referencia al pasado no sea simplemente una manía historicista o un simple manierismo, que sea substancial. Digamos que entre los dos criterios, de corrección y de pertinencia, hay un equilibrio pensado del cual sería difícil fijar de antemano dónde se encuentra exactamente. Se podría hablar de una "negociación" entre el autor del pasado y nuestra lectura actual. Es la razón por la que la reconstrucción integra a menudo un escenario histórico (¿por qué tenemos necesidad ahora de referirnos a un cierto pensamiento histórico?), una narración, que incorpora a su vez una reconstrucción de doctrinas dentro de formulaciones que preparan las tesis que comparamos a través del tiempo.

Hacer referencia a santo Tomás consiste en hacer filosofía, el día de hoy. La preocupación no es principalmente histórica. No se trata de considerar como insensatas las cuestiones actuales de la filosofía, celebrando las del siglo XIII, estimándolas como necesarias y suficientes. Enunciamos al contrario, que en ciertas condiciones, son las mismas. Incluso si se puede tratar de servirse de santo Tomás como un pensamiento exótico, en el tiempo y no en el espacio, un pensamiento capaz de deshacernos de ciertas presuposiciones modernistas, y es hoy que se puede tener este uso. La paradoja de las afirmaciones sobre la existencia de paradigmas inconmensurables con el nuestro, es que solo por el hecho de afirmar esta inconmensurabilidad, la negamos.

Si se parte de la filosofía continental, el idealismo alemán, el neotomismo se ha cons- 
truido de manera obsidional: el tomismo era un castillo con fortaleza asediado por los errores de la modernidad. En cambio, el tomismo analítico no realiza la lectura de santo Tomás como una máquina de guerra contra el pensamiento contemporáneo, sino que adopta una actitud cooperativa dentro de los debates contemporáneos sobre las cuestiones filosóficas mayores, al menos en el cuadro de la filosofía analítica.

Se puede pensar que la idea de reconstrucción está conceptualmente ligada a la idea de verdad en filosofía. Reconstruir, no es solo buscar lo que uno u otro filósofo ha dicho, sino buscar la verdad ${ }^{17}$ dicha. Entonces nos interesamos más en la verdad de las tesis propuestas, que en el hecho (histórico) y los contextos en los cuales han sido expresadas. El tomismo analítico no considera a santo Tomás como indispensable o como un autor que debe seguirse literalmente. Más bien el Aquinate es particularmente interesante, debido a las problemáticas actuales de la filosofía analítica, en metafísica, en filosofía de la mente y en el dominio en el cual fue más esperado, la filosofía de la religión.

\section{El Círculo de Cracovia}

Si se toma la fórmula que cita John Haldane, "el tomismo analítico busca (...) desplegar los métodos y las ideas de la filosofía del siglo veinte -filosofía dominante en los países de lengua inglesa- con relación a la estructura general de las ideas introducidas y desarrolladas por Tomás", esta corresponde perfectamente a la ambición de un grupo de filósofos polacos de los años treinta: Józef Bocheński, Jan Salamucha, Jan Drewnowski y B. Sobociński. Ellos formaban parte del Círculo de Cracovia.

Para explicar lo que es el Círculo de Cracovia, es necesario precisar su vínculo con la Escuela de Lvov-Varsovia, iniciada por Kazimierz Twardowski ${ }^{18}$. M. Schlick, R. Carnap, H. Hahn y O. Neurath son los miembros más representativos del Círculo de Viena, pero antes que ellos ${ }^{19}$, los polacos de la Escuela de LvovVarsovia adoptaron una exigencia metodológica cuyos cuatro elementos fundamentales son el antirrealismo, la precisión de tesis, el rigor de los argumentos y el papel determinante de la lógica ${ }^{20}$. Jan Łukasiewicz y Tadeusz Kotarbiński, principalmente, consideraban la lógica como el instrumento ideal de la filosofía seria, esto es, de la filosofía "científica" 21 . La lógica permite evitar a los filósofos la imprecisión y la confusión verbal. Tiene en ese sentido una misión: enseñarnos el pensamiento preciso y correcto $^{22}$. Este ideal científico condujo finalmente a Łukasiewicz a desesperar de la filosofía. Sus compatriotas llegaron a llamarlo "antifilósofo". Ninguno de los grandes sistemas (Platón, Aristóteles, Descartes, Spinoza, Kant, Hegel) satisfacía a sus ojos las exigencias de rigor y de precisión. Se podría ver un exceso logístico, o incluso una forma de fetichismo del formalismo. Pero conviene insistir sobre el hecho de que esta actitud no se dirige contra la metafísica.

Carnap rechaza los problemas metafísicos en cuanto desprovistos de significado porque, siguiendo a Kant, cuentan solamente como proposiciones metafísicas aquellas que pretenden representar un conocimiento sobre lo que queda completamente afuera de toda experiencia (...). Pero no es ese concepto de la metafísica que nos importa (Łukasiewicz, 1936 -citado por Borkowski, 1970, pp. 229-230).

Finalmente, como algunos metafísicos analíticos actuales, Łukasiewicz se propone entablar la concepción kantiana de la metafísica. En esta concepción, no es el criterio positivista de la verificación empirista el que es decisivo, un criterio heredado de Hume y Kant, sino aquel del conocimiento lógico, manifiesto en Leibniz por ejemplo. Lukasiewicz toma en serio las cuestiones clásicas de la metafísica: naturaleza de lo real, pruebas de la existencia de Dios, problemas del determinismo y de la teodicea. Para él, no son simplemente testimonios de una necesidad metafísica que no puede encontrar satisfacción porque es constitutivamente ligada a una ilusión y agrega: 
El profesor Ajdukiewicz ${ }^{23}$ tenía razón cuando escribió sobre el antiirracionalismo logicista de Polonia, que no conocía ningún filósofo polaco que hiciera suyas las tesis materialistas del Círculo de Viena. Parece que somos demasiado sobrios para eso (Łukasiewicz, 1936 -citado por Borkowski, 1970, p. 233).

La exigencia de cientificidad no conduce entonces a la eliminación de la metafísica desde la forma de un criterio de demarcación entre ciencia y metafísica. Ciertamente, un problema no puede tratarse científicamente si no puede formularse de manera correcta; pero un problema metafísico puede ser claramente formulado $\mathrm{y}$ en ese momento encontrar una auténtica respuesta $^{24}$.

Esta actitud metodológica propia de los filósofos de la Escuela de Lvov-Varsovia, y de Łukasiewicz en particular, se propagó a los filósofos explícitamente católicos. Ellos formarán el Círculo de Cracovia (en los años treinta y hasta la guerra). Nada podía disuadirlos de abordar en el espíritu de la filosofía científica la cuestión de las pruebas de la existencia de Dios. Bocheński no duda en declarar:

Desde su origen, el pensamiento católico ha sido caracterizado por una tendencia hacia la precisión máxima. Si la lógica moderna dispone de instrumentos que, por su actitud, convienen a la física y a las matemáticas, la filosofía católica deberá utilizar sus instrumentos, prosiguiendo así lo que hizo santo Tomás de Aquino cuando desarrolló su sistema sobre una base axiomática (Citado en Puciato, 1993, p.171) ${ }^{25}$.

El programa del Círculo de Cracovia aparece claramente aquí: acoger el trabajo de santo Tomás, siguiendo su espíritu, pero sin psitacismo. Proseguir este trabajo en los términos y con los instrumentos de la filosofía contemporánea -lo que la neoescolástica y el neotomismo no supieron hacer, demasiado preocupados estaban por restablecer la letra de la doctrina tomista en vez de mantener el espíritu de la tradición tomista de pensamiento riguroso-.
El Círculo de Cracovia se ha constituido alrededor de ese proyecto en un Pensamiento católico en relación con la lógica moderna -título de las actas del Encuentro de Filósofos católicos polacos del Tercer Congreso Polaco de Filosofía realizado entre el 24 y el 27 de septiembre de 1936 en Cracovia- ${ }^{26}$. Un texto característico de ese Círculo, es el artículo de Salamucha (1934), "La prueba ex motu de la existencia de Dios: análisis lógico de la argumentación de Santo Tomás". Se trata de una formulación completa de la prueba en términos de lógica cuantificacional y de la teoría de las relaciones. Los miembros del Círculo de Cracovia estiman que su uso de la lógica simbólica los acerca de una manera más segura a la tradición medieval que a la reanudación de santo Tomás como antídoto o complemento al pensamiento moderno (Descartes, Kant, Hegel). La lógica se consideró entonces el instrumento de la ontología general, es decir, del estudio de todas las entidades reales, ya sean actuales, posibles o ideales.

En "La neoescolástica y las exigencias de la ciencia moderna" ${ }^{27}$, Drewnowski sin duda ha dado las bases teóricas más explícitas de ese "tomismo analítico" polaco. Él castiga la crítica del virus logisticum de aquellos para los cuales la filosofía católica debería por principio desconfiar de los instrumentos intelectuales que elaboran los no católicos. El menosprecio de esos instrumentos intelectuales equivale a reanudar algunas críticas en contra de santo Tomás en la mitad del siglo XIII; estas visaban rechazar los préstamos por parte de los teólogos a la filosofía pagana y musulmana ${ }^{28}$.

Para hablar generalmente, el efecto de este malentendido es un bajo nivel científico de la filosofía contemporánea elaborada por los católicos, principalmente si se compara con la excelencia científica que era la de la época de santo Tomás (Drewnowski, 1937, p. 222).

Mientras que la Suma teológica era el súmmum del rigor científico, la neoescolástica se desarrolla en la forma "de bellos ensayos al límite entre la ciencia y el arte" (Drewnowski, 
1937, p. 223). La philosophia perennis debe situarse al más alto nivel; como en la Edad Media, debe ser la summa de todo el conocimiento moderno (p.223).

La doctrina de la analogía explica cómo podemos decir alguna cosa de Dios. Drewnowski cree reformular en términos de una teoría del isomorfismo que la lógica permitía expresar con rigor y precisión.

Drewnowski considera que las presentaciones escolásticas no soportan la comparación, en rigor y precisión, con aquellas que permiten los instrumentos de la lógica moderna (Drewnowski, 1937, p. 226). Que él sobrestime la lógica moderna o que subestime la antigua, los trabajos recientes de algunos historiadores de la lógica medieval pueden dejarlo creer $^{29}$. Pero para darse cuenta, todavía era necesario hacer la comparación y percibir la lógica medieval a través de la lógica moderna. Jan Salamucha prueba, desde 1937, que la mayor parte de los manuales de lógica (supuestamente) escolástica contiene algunos principios que no se encuentran ni en santo Tomás ni en Juan de Santo Tomás. Es así la distinción entre el contenido y la extensión del concepto. Es primero que todo generada por la distinción entre comprensión y extensión en la Lógica de Port-Royal. Está en un buen lugar en $\mathrm{Kant}^{30}$, y... en ciertos manuales de lógica "escolástica", donde está presente como una evidencia escolástica ${ }^{31}$.

\section{¿Teo-lógica?}

Ryszard Puciato (1993) afirma que "no es posible formalizar la estructura del ser, porque la lógica captura solamente sus relaciones externas" (p. 183). Sin duda quiere decir que el esse tomista no se reduce a una variable que podría colocarse en lugar de $x$ después del cuantificador existencial, entrando así en las relaciones estrictamente externas entre las entidades que no son tomadas en su ser mismo. La doctrina tomista prevé no solamente lo que los hace ser lo que son (la esencia), sino lo que hace que sean (el ser) -su relación de participación con el ser divino-32. Esta relación no es en estricto externa. De todos modos, sí es un problema imposible de examinar aquí en detalle, la idea importante es que los medios lógicos de las reconstrucciones lógicas de los tomistas analíticos polacos son probablemente insuficientes para captar la naturaleza exacta de esta relación. Empujar el argumento más lejos equivaldría a decir que la lógica russelliana (o algún otro sistema de lógica) no puede erigirse en norma decisiva de la corrección teológica. Tal crítica, si es seria, minimiza sin embargo la posibilidad de una lógica formal adaptada en este aspecto de la doctrina del ser en santo Tomás. Después de todo, nada impediría a los tomistas hacer de la lógica la sirvienta de la teología, siempre que, en ese papel sea creíble ${ }^{33}$.

Por mi parte, la debilidad constitutiva del tomismo analítico en su versión polaca me parece que reside todavía más en la identificación del rigor con el formalismo lógico. El ideal científico que preside a esta identificación equivale a decir que una prueba, en cualquier dominio, debe tener la forma de una prueba lógico-matemática. Pero este ideal no ha sido él mismo justificado. El argumento según el cual santo Tomás buscaría el más grande rigor posible deja también incierto el sentido del término "rigor". ¿Se trata exactamente de la lógica formal moderna? ¿No se podría pensar que la formalización de las pruebas tomistas cambie en nada la irremediable confusión conceptual de la teología natural? Esta confusión concierne al uso de los términos que se utilizan cuando se trata por ejemplo de la formalización de la prueba ex motu de la Suma contra los gentiles (I, 13): "Dios", "acto, "potencia", "mover", "ser movido", etc. ¿No existe una forma de confusión intelectual que se elude por un rigor lógico?

Bien o mal, una tal cohabitación peligrosa entre rigor formal y confusión conceptual ha sido diagnosticada por Wittgenstein (en Segura, 2007) en el caso de la teoría (cantoriana) de los conjuntos transfinitos. Términos antiguos y 
familiares se emplean con un significado nuevo e incierto.

Y si se dice que un número infinito es más grande que uno finito, eso no hace a estos dos números comparables, puesto que en este enunciado, la expresión "más grande" tiene otro significado que, digamos, en la proposición $5>4$ (pp. 918-919).

La diferencia entre el finito y el infinito para Wittgenstein es una entre dos tipos de cálculos. El logro de un cierto cálculo, aquel de la teoría de los conjuntos, no es un espacio en blanco que debe conducirnos a creer que comprendemos lo que decimos hablando del infinito. La consecución de una técnica o de un cálculo no es una garantía contra las confusiones conceptuales. Wittgenstein (en Segura, 2007) agrega:

Cuando se requiere la ineptitud humana para simbolizar directamente el infinito, la teoría de los conjuntos introduce en su propio cálculo el más grande error de interpretación que podamos imaginar. Por supuesto, es precisamente esta interpretación que es responsable de la invención del cálculo (p. 474).

Una teología natural fascinada por la idea de que los cálculos lógicos aportarían ellos mismos todo el rigor deseado, vehicula tal vez la misma confusión intrínseca entre rigor formal y rigor conceptual. No es porque un cálculo funciona que se ha eliminado la imprecisión y la confusión. De un modo general, "analítica" no debe confundirse con "formal". Una filosofía analítica procede por análisis de conceptos, y en ese sentido, hay filósofos analíticos mucho antes que haya una "filosofía analítica". Aristóteles es desde este punto de vista un filósofo analítico, incluso si su metafísica no es particularmente formal. En cambio, una confianza ciega en los métodos formales, tiene el riesgo de conducir a subestimar el análisis conceptual como indispensable método crítico en el uso de formalismos. Sin embargo, estas observaciones no deben comprometerse en el sentido de un antiformalismo, como el desarrollado por Descartes por un prejuicio común en su época, la esterilidad de la lógica formal. Se puede pensar que el rigor analítico y el rigor formal no se recubren y que la lógica es, para la filosofía, garante de la verdad, porque es el instrumento privilegiado gracias al cual se puede evitar los errores ${ }^{34}$.

El proyecto fundamental del Círculo de Cracovia, aquel de una reconstrucción del tomismo, es finalmente la síntesis de las concepciones logísticas heredadas de Russell y Łukasiewicz. Esta observación no constituye ciertamente una crítica sin matiz de los esfuerzos de los miembros del Círculo de Cracovia. No solo la intención era elogiable, sino el proyecto tenía el mérito de romper de modo radical con todo lo que el neotomismo tenía de estrecho. Un mejor conocimiento del Círculo de Cracovia constituirá un progreso histórico en la aprehensión de la historia de los tomistas en el siglo XX.

\section{El tomismo en la filosofía de la religión}

Los tomistas lógicos del Círculo de Cracovia sobrestiman el aspecto sintáctico de las pruebas de santo Tomás, a expensas de sus características semánticas. La credibilidad de las pruebas supone que nos aseguremos que los términos "Dios" o "alma", por ejemplo, tengan un sentido. Para Anthony Kenny,

[...] la teología natural es algunas veces definida como consistente en la tentativa de proporcionar pruebas o argumentos a favor de la existencia de Dios. Esta definición es más bien estrecha: la teología natural debería también incluir otras cosas. Debería incluir la tentativa de identificar al menos algunos atributos de Dios, defender la coherencia de esos atributos entre ellos y la compatibilidad de la existencia de Dios con lo que sabemos del mundo. No solamente la teología natural debe preocuparse de la verdad de los enunciados de Dios, también de que tengan sentido. Ya que si no tienen sentido, no podrán ser verdaderos (Kenny, 1992, pp. 67-68). 
De ahí la emergencia desde hace medio siglo de una filosofía analítica de la religión en la cual el proyecto de teología natural, de un discurso sobre Dios, su naturaleza, su existencia y sus atributos, se encuentre defendido y justificado.

La emergencia de esta filosofía de la religión supone la distinción entre: la teología revelada, que va desde Dios hacia al hombre, es decir, que va de arriba a abajo; la teología dogmática, que es ella misma la codificación de artículos de fe extraídos de la Revelación; y la teología filosófica, que es la parte de la filosofía necesariamente ancilla theologiae, en la medida que consiste en una clarificación argumentativa del contenido mismo de la Revelación. La mayor parte de teólogos medievales han practicado la teología filosófica, en el sentido que se indica aquí. Por lo tanto, la filosofía, en cuanto se trata de teología filosófica, depende de las verdades reveladas. La peculiaridad de santo Tomás es haber practicado la teología natural, una filosofía independiente de las verdades reveladas pero que trata las cuestiones de verdades religiosas; va de abajo hacia arriba ${ }^{35}$ y no tiene por aceptado ninguna proposición doctrinal revelada. Santo Tomás también practicó la filosofia simplemente. Ya que debió concentrarse en temas cuyo tratamiento es indispensable para el desarrollo de la teología natural. Son asuntos sobre la naturaleza de las cosas (metafísica), sobre la naturaleza de la mente (filosofia de la mente) y sobre las acciones humanas (filosofía de la acción) ${ }^{36}$.

La teología natural era tradicionalmente considerada como un elemento de la metafísica, con la cosmología y la psicología racional. Hoy, es más bien como una parte de la filosofía de la religión que toca concebirla. Pasa por materias epistemológicas tratando la racionalidad de las creencias religiosas en general y ciertas creencias particulares (la creencia de los milagros, por ejemplo). Entra en las cuestiones sobre los lazos entre ciencia y religión, entre moralidad y religión, en la pluralidad de las religiones. Como lo apunta Kenny, supone una reflexión sobre la posibilidad de un discurso religioso, el sentido de la palabra "Dios", aquel de la noción de eternidad, etc. No sabría tampoco abandonar las temáticas sobre la realidad del mal, sin duda la más grande dificultad que el teísmo debe afrontar. Al interior de la filosofía analítica de la religión, el tomismo analítico es la defensa de las tesis inspiradas en santo Tomás.

Se podría oponer que nadie habla del kantismo analítico a propósito de filósofos analíticos que parecen tener una predilección por la filosofía de Königsberg, como Peter Strawson o últimamente John McDowell. Nadie habla tampoco de humismo analítico para defender en el interior de la filosofía analítica, las posiciones humanianas de John Mackie o, en algunos aspectos, de David Lewis. Es sin duda que dentro del tomismo hay más que una simple posición filosófica. Es por lo general una filosofía de creyente. Entonces se le sospecha, típicamente moderno hay que decirlo, de que aquel que cree, que parte de la verdad revelada, se convierte en un inepto para la filosofía. No puede hacer de la filosofía su creencia religiosa.

Ahora bien, santo Tomás ha propuesto algo muy importante sobre ese punto. La investigación filosófica que se encuentra dentro de la teología natural busca dar razón de nuestras creencias religiosas y justificarlas racionalmente si nos las contradicen. Pero Tomás no piensa que basta con que se justifiquen para ser reconocidas como verdaderas. La fe es libre y por lo tanto, es también el asentimiento del creyente requerido para la $\mathrm{fe}^{37}$. Si la fe es un don de la Gracia, no es una limitación intelectual. Que una primicia se acepte, que se tenga como razonable de creer que esta primicia implica una conclusión, eso no significa que se va a creer, realmente creer, esta conclusión ${ }^{38}$. Realmente creer, sería actuar en consecuencia. El esfuerzo de racionalidad no puede nada contra la acracia religiosa. Solamente la Gracia es eficaz ${ }^{39}$. Pero eso no implica que la fe sea irracional, como lo piensa el fidelista, o que tendría que necesariamente vencer una resistencia de la razón. Razón 
y fe no se oponen, podemos justificar las creencias religiosas, incluso si esta justificación no se identifica evidentemente en la fe. El tomismo puede así partir de su fe sin que incluya colocar la búsqueda racional de la verdad de un lado, o partir en búsqueda de la verdad decidiendo entonces que debería, si eso tiene sentido, hacer como si no tuviera fe.

¿Cómo explicar entonces que Kenny, presentado como el más alto tomista analítico, pueda ser agnóstico? En el dominio de la filosofía de la mente, las tesis que él defiende son netamente tomistas. Son las tesis que necesitamos para la justificación de creencias religiosas sin la ayuda de la Revelación. Si estas pueden realizar ese papel, es porque son verdaderas en ellas mismas y no únicamente por su solo uso. Es la razón por la cual no es imposible que un agnóstico como Kenny (1992) sea un tomista analítico. La fe no es evidentemente deducible de las afirmaciones de santo Tomás sobre lo que es una mente o sobre la elección racional. Es entonces, cuando parece ser posible defender un tomismo agnóstico. Quizá es también un tomismo anémico.

El tomismo analítico del Círculo de Cracovia era una reconstrucción de ciertas pruebas centrales dentro de la teología natural de santo Tomás. Era un tomismo de base estrecha, en estricto lógico. El tomismo que se ha desarrollado en la filosofía analítica tiene un soporte más largo. Integra la metafísica, la filosofía de la mente y la filosofía de la acción y de la sociedad. En todos esos dominios, hace entrar las tesis tomistas en el debate filosófico actual. Respecto a eso, el libro publicado por J. C. Smart y John Haldane (1996), Atheism and theism, es ejemplar. Ya que Smart (el ateo) y Haldane (el creyente) comparten la misma concepción del trabajo filosófico, sus argumentos se corresponden. No son dos discursos paralelos e incompatibles. Que sean los dos realistas metafísicos (existe un mundo independiente de nosotros) constituye un elemento común a partir del cual el debate puede realmente desplegarse. Pero eso no hubiera bastado a mi parecer si
Haldane no hubiera dado a los argumentos tomistas la forma que podemos alcanzar en un debate contemporáneo sobre la cuestión de la evolución o sobre la irreductibilidad de las propiedades mentales a las propiedades físicas. Es en ese sentido que la filosofía analítica constituye una lingua franca ${ }^{40}$, y que el tomismo analítico se ha convertido en analítico.

\section{Universidad de Nancy II y Archivos Poincaré (CNRS).}

\section{Notas}

${ }^{1}$ Ciertamente se puede decir que santo Tomás es antes que todo un teólogo, colocar el acento sobre sus comentarios bíblicos y su atención a los Padres de la Iglesia, es tener poco interés por un Tomás como eslabón de la tradición aristotélica. Sería sin embargo excesivo afirmar que Tomás no puede ser verdaderamente un filósofo porque es un teólogo. ¿Se diría que Aristóteles no es finalmente un biólogo?, ¿Hume un historiador?, ¿Frege un matemático?, ¿incluso si cada uno de ellos es también biólogo, historiador y matemático?

${ }^{2}$ El artículo fue publicado en la Revue de Métaphysique et de Morale en 1931.

${ }^{3}$ Sobre este debate, confróntese McInerny (1993), también Fitzpatrick (1982); McCool (1994).

${ }^{4}$ Sobre los problemas franceses del neotomismo al comienzo del siglo XX, ver Colin (1997). Este autor muestra la importancia de la encíclica Pascendi Dominici Gregis de 1907 en la lucha de la iglesia contra el modernismo filosófico y social.

${ }^{5}$ En este aspecto, Die philosophie der vorzeit verteidigt (1853-1860), de J. Kleutgen, jesuita alemán profesor en Roma, ha desempeñado un papel relevante en la oposición de la filosofía antigua y medieval a la filosofía moderna cuyo héroe sería Descartes. 
6 "Tanto Brentano como Bolzano, despreciaban el idealismo alemán y buscaban la claridad y la proximidad con los ideales metodológicos de las ciencias naturales. Brentano poseía una profunda cultura histórica, un conocimiento de Aristóteles y de los escolásticos, a los cuales testimoniaba respeto, un ejemplo que será menos seguido en Austria que en Polonia" dice P. Simons (1992, pp. 6-7). Lo anterior aparece también claramente en Smith (1994).

${ }^{7}$ El título de "tomismo analítico" no es controlado y no es seguro que todos esos filósofos aceptarían que sus trabajos ingresen con este nombre.

${ }^{8}$ También se puede pensar en el libro de Anscombe y Geach, 1973.

${ }^{9}$ De los cuales, entre Ockham y Fodor, Panaccio (1991).

${ }^{10}$ Según Nef (1993), "lo que aparece entonces de manera muy sorprendente como una verdadera Edad Media (en el sentido estricto y casi peyorativo), para la semántica, es el periodo moderno, es decir, aquel que va del siglo XV a finales del siglo XIX" (p. 6). Libera (1996) afirma también que "es la filosofía clásica que se convierte en la Edad Media, ella que da espacio y separa, por sus propios medios, el periodo medieval y la modernidad: no se puede entonces decir que la Edad Media anuncia, sino que la Edad clásica interrumpe (p. 447).

${ }^{11}$ Por ejemplo, se percibe al leer su comentario de las Epístolas a los hebreos (debo esta observación a Cyrille Michon).

${ }^{12}$ Estas observaciones no tienen ninguna pretensión histórica sobre el estatus exacto de los diferentes tipos de escritos en la universidad medieval. Ver Kenny y Pinborg (1987); Marenbon (1987).

${ }^{13}$ Confróntese también Panaccio (2000).
${ }^{14}$ Se puede por supuesto tener varias interpretaciones analíticas y fenomenológicas de Aristóteles.

${ }^{15}$ Sobre esta cuestión en Quine, confróntese Laugier-Rabaté, 1992, pp. 93-117.

${ }^{16}$ Tomo prestado las nociones de fidelidad y pertinencia de C. Panaccio, pero empleándolas un poco diferente.

${ }^{17}$ Más allá del tema de saber si se debe interrogar sobre la verdad de lo que dicen los filósofos, cuestión a la cual hemos intentado responder afirmativamente, se plantea el asunto más general de la relación entre significado y verdad, aquella de saber si comprender una frase no supone conocer sus condiciones de verdad.

${ }^{18}$ Confróntese Woleński, 1985, 1989.

${ }^{19}$ El "manifiesto" del Círculo de Viena se publicó treinta y cuatro años después de que Twardowski comenzara a enseñar a Lvov. Sobre ese punto, confróntese Woleński, 1989, pp. 296-302.

${ }^{20}$ Esta última característica vale más para los varsovianos después de 1918 (Alfred Tarski, por supuesto) que para Twardowski. 1993.

${ }^{21}$ Confróntese Coniglione, Poli y Woleński,

${ }^{22}$ Confróntese Pouivet, 2000.

${ }^{23}$ Otra figura eminente de la Escuela de Lvov-Varsovia, antes y después de la Segunda Guerra Mundial.

${ }^{24}$ La cuestión de las relaciones entre determinismo y libertad y la defensa del libre arbitrio preocuparon en particular a Łukasiewicz toda su vida. Al final de su libro La Syllogistique d'Aristote (1951, traducción francesa en F. Caujolle-Zaslavsky, 1972), indica que "si el tratamiento aristotélico de la necesidad desem- 
boca $[. .$.$] en un fracaso, su concepto de posibi-$ lidad indiferente o de contingencia es una idea importante y fructuosa; y creemos que proporciona una refutación eficaz del determinismo" (p. 211).

25 Esta citación se sacó del artículo "Tradycja myśli katolickiej a ścistośé" ("La tradición del pensamiento católico y la exactitud").

${ }^{26}$ Las actas se publicaron (en francés) en 1937 por la Facultad de Teología de la Universidad Jaguelónica de Cracovia.

27 "Neoscholastyka wobec nowoczesnych wymagań nauki”, en K. Michalski, Myśl katolicka wobec logiki współczesnej, Actas del Encuentro de Filósofos polacos católicos en 1937, publicadas en Poznan. En inglés con el título "Neoscholasticism and the demands of modern science", trad. R. Puciato, 1993.

${ }^{28}$ Alusión a la condena de 219 tesis por el obispo Étienne Tempier el 7 de marzo de 1277. Incluso si estaban dirigidas contra Siger de Brabant y Boecio de Dacia, algunas de las 129 proposiciones tocaban a Tomás de Aquino (particularmente las proposiciones 46 y 110 que condenan la individuación por la materia). Con el pretexto de rechazar la tesis que no hay estado superior al ejercicio de la filosofía (quod non est excellentur status quam vacare philosophiae) y una forma de racionalismo naturalista, en especial en moral, doctrinas que en efecto se extendían, era la idea misma de filosofía que se criticaba.

${ }^{29}$ Confróntese Geach, 1962; Broadie, 1993.

${ }^{30}$ En su Lógica (§7), en la cual confía la tarea de la redacción a G. B. Jäsche, que la publica en 1800 .

${ }^{31}$ Por ejemplo, el padre Collin, 1926, § 12. Siguiendo al padre Collin, la doctrina aristotélica de las categorías estaría fundada en esta distinción. Análisis psicológico, análisis lingüístico y análisis lógico son "sabiamente" confundidos: las ideas son elementos de la proposición, de atributos e incluso de predicados. $\mathrm{La}$ noción de idea del padre Collin es más o menos aquella de Locke, pero más vaga, si es posible. Por otro lado, el padre Collin jura fidelidad y obediencia a santo Tomás. (El párrafo 28 utiliza un ejemplo de Ockham para hacer asumir a santo Tomás una teoría silogística en términos casi conjuntos). La consulta de otras obras "tomistas" de la misma época, deja pensar que el padre Collin, cuya obra tiene también méritos, no es un caso aislado de similares confusiones.

${ }^{32}$ Es todo el problema de la relación entre Tomás y el neoplatonismo.

${ }^{33}$ Se puede imaginar una situación semejante a aquella que ha visto la elaboración de sistemas de lógica modal adaptados a la expresión rigurosa de diferentes metafísicos de las modalidades.

${ }^{34}$ Confróntese Agazzi, 1986.

${ }^{35}$ Kretzmann, 1997, cap. 2, donde habla de "theology from the bottom up".

${ }^{36}$ Santo Tomás separa entonces las cuestiones filosóficas de las cuestiones teológicas, incluso si las articula. Para él, la teología filosófica es ancilla theologiae, pero la filosofía en cuanto a ella no lo es. Ver R. Pouivet, 1997a, pp. 104-110.

${ }^{37}$ Suma teológica, IIaIIae, 6, 1.

${ }^{38}$ Tomo esta idea, expresada en otro contexto, de Engel, 1998.

${ }^{39}$ Suma teológica, IIaIIae, 5, 2.

${ }^{40}$ Tomo la expresión de R. McInerny en sus “Opening remarks" en el Summer Thomistic Institute 1998 de Jacques Maritain, Centro de la Universidad de Notre Dame. 


\section{Referencias}

Agazzi, E. (1986). La logique et le problème de la rigueur. En J. Vuillemin (Ed.), Mérites et limites des méthodes logiques en philosophie (pp. XX-XX). París: Vrin.

Anscombe, G. E. M. \& Geach, P. (1973). Three philosophers, Aristotle, Aquinas, Frege. Oxford: Blackwell.

Borkowski, L. (Ed). (1970). Selected Works. Ámsterdam: Holanda septentrional

Boss, G. (Ed). (1994). De la reconstruction en histoire de la philosophie. En La philosophie et son histoire. Zúrich: Éditions du Grand Midi.

Broadie, A. (1993). Introduction to medieval logic (2nd ed). Oxford: Clarendon Press.

Caujolle-Zaslavsky, F. (1972). La Syllogistique d'Aristote. París: Colin

Colin, P. (1997). L'audace et le soupçon. La crise du modernisme français dans le catholicisme français, 1893-1914. París: Desclée de Brouwer.

Collin, M. (1926). Manuel de philosophie thomiste (T.1). París: Téqui.

Coniglione, F., Poli, R., \& Woleński, J. (1993). Polish Scientific School. Ámsterdam: Rodopi.

Drewnowski, J. F. (1937). Neoscholasticism and the demands of modern science. Axiomathes, 4(2), 220-226. doi: 10.1007/ BF02229797

Engel, P. (1998). La logique peut-elle ouvrir 1'esprit?, Dialogue, 1(38), 1-27.

Fitzpatrick, P. J. (1982). Neosholasticism. En N. Kretzmann, A. Kenny, J. Pinborg \&
E. Stump (Eds), The Cambridge History of Later Medieval Philosophy (pp. 838852). Cambridge: Cambridge University Press.

Geach, P. (1962). Reference and generality, an examination of some medieval and modern theories. Ithaca: Cornell University Press.

Haldane, J. (1997). Analytical thomism: a prefatory note. The Monist, 80(4), p. 486.

Helm, P. (1997). Faith and understanding. Michigan: Wm. B. Eerdmans Publishing Company.

Kenny, A. (1992). What is faith? Essays in the philosophy of religion. Oxford: Oxford University Press.

Kenny, A. \& Pinborg, J. (1987). Medieval philosophical literature. En N. Kretzmann, A. Kenny, J. Pinborg \& E. Stump (Eds), The Cambridge History of Later Medieval Philosophy (pp. 9-42). Cambridge: Cambridge University Press.

Kerr, F. (2002). After Aquinas, versions of Thomism. Oxford: Blackwell.

Kretzmann, N. (1997). The metaphysics of theism. Oxford: Oxford University Press.

Laugier-Rabaté, S. (1992). L'anthropologie logique de Quine. París: Vrin.

Libera de, A. (1996). La querelle des universaux. París: Seuil.

Marenbon, J. (1987). Later medieval philosophy (1150-1350). Londres: Routledge \& Kegan Paul,

McCool, G. (1994). The neo-thomists. Milwaukee: Marquette University Press. 
McInerny, R. (1993). Reflections on christian philosophy. En L. Zagzebski, (Ed), Rational Faith (pp. 273-330). Notre Dame: University of Notre Dame Press.

Michon, C. (1996). Asymétries, Thomas d'Aquin et Guillaume d'Occam précurseurs de Frege. Les études philosophiques, 3, 307-321.

Nef, F. (1993). Le langage. París: Bordas.

Panaccio, C. (1991). Les mots, les concepts et les choses. La sémantique de Guillaume d'Occam et le nominalisme d'aujourd'hui. Montreal: Bellarmin.

Panaccio, C. (1994). De la reconstruction en histoire de la philosophie. En Boss, G. (Dir). La philosophie et son histoire (pp. 173195). Zúrich: Éditions du Grand Midi.

Panaccio, C. (2000). Philosophie analytique et histoire de la philosophie. En P. Engel (Dir.), Précis de philosophie analytique (pp. 325-344). París: Presses Universitaires de France.

Pouivet, R. (1997a). Après Wittgenstein, saint Thomas. París: Presses Universitaires de France.

Pouivet, R. (1997b). La reconstruction du nominalisme chez N. Goodman. En J.-J. Vienne (Ed.), Philosophie analytique et histoire de la philosophie (pp. 267-284). París: Vrin.
Pouivet, R. (2000). Aristote, Łukasiewicz et le príncipe de contradiction, presentación de la edición francesa de J. Łukasiewicz, $D u$ principe de contradiction chez Aristote (traducción francesa). París: D. Sikora, L'Eclat.

Puciato, R. (1993). Thomism and Modern Formal Logic: Remarks on the Cracow Circle. Axiomathes, 4(2), 169-191. doi: 10.1007/BF02229794

Salamucha, J. (1934). Dowód ex motu no istnienie Boga. Analiza logiczna argumentacji św. Tomasza Collectanea Theologica, 15(4), 53-90.

Segura, L. F. (2007). Gramática filosófica. México: Instituto de Investigaciones Filosóficas, Universidad Nacional Autónoma de México.

Simons P. (1992). Philosophy and logic in Central Europe from Bolzano to Tarski., Dordrecht: Kluwer.

Smart, C \& Haldane, John. (1996). Atheism and theism. Oxford: Blackwell.

Smith, B. (1994). Austrian philosophy. Chicago: Open Court.

Woleński, J.(1985). Filozoficzna Szkola Lwowsko-Warszawska. Varsovia: Państwowe Wydawnictwo Naukowe

Woleński, J. (1989). Logic and philosophy in the Lvov-Warsaw School. Dordrecht: Kluwer. 